\title{
Electron spin resonance spectroscopic measurement of antioxidant activity of organic solvent extracts derived from the methanolic extracts of Sri Lankan thebu leaves (Costus speciosus)
}

\author{
Kalpa W. Samarakoon ${ }^{1,2^{*}}$, H.H. Chaminda Lakmal ${ }^{1,2}$, Seo Young Kim ${ }^{1}$ and You-Jin Jeon ${ }^{1}$ \\ ${ }^{I}$ Department of Marine Life Science, Jeju National University, Jeju 690-756, Republic of Korea. \\ ${ }^{2}$ Department of Chemistry, Faculty of Science, University of Colombo, Colombo 03.
}

Revised: 29 January 2014; Accepted: 26 February 2014

\begin{abstract}
In this study, the antioxidant effects of different solvent soluble fractions derived from the methanolic extracts of the Sri Lankan thebu plant (Costus speciosus) leaves were assessed. For the antioxidant activity of the extracts, 2,2-diphenyl-1-picrylhydrazyl (DPPH), hydroxyl and alkyl radical scavenging potentiality were measured using electron spin resonance (ESR) spectroscopy compared to the standard antioxidant ascorbic acid. Among the extracts, ethyl acetate fraction (T-EA) indicated the strongest scavenging activity against hydroxyl and alkyl radicals with the $\mathrm{IC}_{50}$ values 0.046 \pm 0.002 and $0.055 \pm 0.004 \mathrm{mg} \mathrm{mL}^{-1}$, respectively. The aqueous fraction (T-WE) indicated the highest DPPH radical scavenging activity $\left(\mathrm{IC}_{50}\right.$ value $\left.0.110 \pm 0.01 \mathrm{mg} \mathrm{mL}^{-1}\right)$. The total phenolic content in thebu extracts was the highest in T-EA fraction with $6.57 \%$. Moreover, both T-EA and T-WE fractions did not show any significant cytotoxic effect against vero cells in vitro assays. These results indicated the profound antioxidant effects of the Sri Lankan thebu leaf extracts for the first time. Isolation of antioxidative compounds from T-EA and T-WE fractions and in vitro antioxidant effects can be considered in further studies.
\end{abstract}

Keywords: Antioxidant activity, Costus speciosus, electron spin resonance, medicinal plants, thebu leaves.

\section{INTRODUCTION}

Reactive oxygen species (ROS) are involved in many diseases and these reactive molecules are formed during physiological processes (Heo \& Jeon, 2008). ROS are unstable free radicals such as hydroxyl $\left({ }^{\circ} \mathrm{OH}\right)$, nitric oxide ( $\left.\mathrm{NO}^{*}\right)$, peroxyl (ROO') and superoxide $\left(\mathrm{O}_{2}{ }^{\circ}\right)$, and commonly generated with the excessive metabolic oxygen. Under normal physiological conditions, ROS are effectively eliminated by natural endogenous antioxidant enzymes such as superoxide dismutase (SOD), catalase (CAT) and glutathione peroxidase (GPx) (Kim et al., 2007). Non-enzymatic antioxidants such as vitamin C, $\alpha$ tocopherol and selenium are also involved in protecting internal organs and tissues from ROS. However, under certain conditions, imbalances between the antioxidant system and the ROS can result in damage to the biological tissues and macro bio-molecules such as proteins, lipids and nucleic acids (Qian et al., 2008). This phenomenon is known as oxidative stress and can be associated with many degenerative diseases of ageing, such as cancers, coronary heart diseases and atherosclerosis (Finkel \& Holbrook, 2000).

These disorders are increasing due to certain conditions such as environment pollution, chemicals of smoke, alcohol and high-fat diets. Researchers are continually seeking a good source with potent antioxidant ability as an alternative for the dietary supplements. Medicinal plants are considered as a rich source of natural antioxidants (Li et al., 2008) and have been used to treat chronic diseases many centuries ago. In particular, South Asian and Asia Pacific countries have utilized medicinal plant materials expecting health benefits and long life (Inayatullah et al., 2012). Therefore, many researchers attempt to evaluate the therapeutic potential of medicinal plants, as they are rich in phytochemicals (Chen et al., 2008). In fact, antioxidant compounds are potential candidates for future drug discovery and considered as 
alternative possibilities in pharmacological applications. Costus speciosus Koen is an ornamental plant well known as Thebu (Sinhala), Spiral flag (English), Keu or Keukand (Hindi), Kembu (Sanskrit) and Kostam (Tamil) (Srivastava et al., 2011). It belongs to the order Zingiberales and family Zingiberaceae. The rhizomes of the Zingiberaceae family are importantly being used in many Asian countries and their medicinal properties have been broadly discussed. In Sri Lanka, the thebu plant is very popular in home gardens and its leaves are traditionally consumed as a green leaf salad. Different parts of the plant such as the rhizomes, stem, flowers and roots are applied in Ayurvedic therapy and have been used in folk medicine for a long time. The knowledge of the health benefits of thebu plant is higher among the Sri Lankans who believe that it can cure diabetics and other chronic diseases. Bandara et al. (1989) have reported the isolation of methyl 3-(4-hydroxyphenyl)2-(E)-propenoate from Sri Lankan C. speciosus through the screening of antifungal activity among 63 medicinal plant extracts. Another study that evaluated steroidal sapogenins from Sri Lankan plant species revealed that the rhizome of $C$. speciosus was the best material for isolating sapogenins (Gunathilaka et al., 1978). A recent study reported that methanol and water extracts of the C. speciosus leaf effectively reduced the insulin resistance in experimental wistar rats (Subasinghe et al., 2012). Despite the facts, the biological and chemical evaluation of the Sri Lankan thebu plant leaf has not been carried out so far. This research attempts to evaluate the antioxidant activities of the Sri Lankan thebu plant leaves derived organic solvent extracts, through free radical scavenging activities using electron spin resonance spectroscopy. In addition, the cytotoxic effect of the thebu extracts against vero cells has also been determined in vitro.

\section{METHODS AND MATERIALS}

\section{Chemicals and reagents}

5,5-Dimethyl-1-pyrrolin N-oxide (DMPO), 2,2-azobis (2-amidinopropane) hydrochloride (AAPH), $\alpha$-(4pyridyl-1-oxide)-N-t-butylnitrone (POBN) and 1,1diphenyl-2-picrylhydrazyl (DPPH) were purchased from the Sigma Chemicals Co. (St. Louis, USA). Dulbecco's modified Eagle's medium (DMEM), fetal bovine serum (FBS) and streptomycin-penicillin was purchased from Gibco (Gaithersburg, MD). All the other reagents were of the highest commercially available grade.

\section{Sample collection and preparation}

Thebu plant (Costus speciosus) leaf samples were collected from Maharagama area in the Western Province of Sri Lanka and the authenticated specimen was kept in the Research Laboratory, Department of Chemistry, University of Colombo for identification. The samples were washed well and dried at room temperature for $24 \mathrm{~h}$. The leaves were cut into smaller pieces and stored at $-75{ }^{\circ} \mathrm{C}$. The sample $(310.6 \mathrm{~g})$ was ground into a fine powder in a laboratory mechanical blender and homogenized. The homogenized leaf sample in $80 \%$ methanol was sonicated (ultra-sound assisted extraction) at $25{ }^{\circ} \mathrm{C}$ for 90 min periods three times. The extract was filtered in a vacuum using Whatman No.1 (Whatman Ltd., Maidenstone, England) filter paper and the solvent was evaporated using a rotary evaporator (Fisher Scientific, Loughborough, UK). The collected crude methanolic extract (T-ME; $4.25 \mathrm{~g}$ ) was separated into four different fractions: $n$-hexane (T-HE; $1.56 \mathrm{~g}$ ), chloroform (T-CE; $1.28 \mathrm{~g}$ ), ethyl acetate (T-EA; $0.84 \mathrm{~g}$ ) and aqueous (T-WE; $0.35 \mathrm{~g})$, respectively.

\section{Determination of the total phenolic content}

The total phenolic content was determined according to Chandler and Dodds (1983). One milliliter of the sample was mixed in a test tube containing $1 \mathrm{~mL}$ of $95 \%$ ethanol, $5 \mathrm{~mL}$ of distilled water and $0.5 \mathrm{~mL}$ of 50 $\%$ Folin-Ciocalteu reagent. The mixture was allowed to react for $5 \mathrm{~min}, 1 \mathrm{~mL}$ of $5 \% \mathrm{Na}_{2} \mathrm{CO}_{3}$ was added, mixed thoroughly and placed in the dark for $1 \mathrm{~h}$. The absorbance was measured at $725 \mathrm{~nm}$ using a UV-VIS spectrometer. A gallic acid standard curve was obtained for the calibration of phenolic content.

\section{DPPH radical scavenging assay}

2,2-diphenyl-1-picrylhydrazyl (DPPH) is a free radical donor, which can be detected via electron spin resonance (ESR) spectrometry (JES-FA machine, JOEL, Tokyo, Japan) by the technique described by Nanjo et al. (1996). $40 \mu \mathrm{L}$ of each sample was added into $40 \mu \mathrm{L}$ of DPPH (60 $\left.\mu \mathrm{mol} \mathrm{L} \mathrm{L}^{-1}\right)$ in ethanol. After $10 \mathrm{sec}$ of vigorous mixing, the solutions were transferred into $100 \mu \mathrm{L}$ teflon capillary tubes and fitted into the cavity of the ESR spectrometer. The spin adduct was determined on JES-FA ESR spectrometer exactly $2 \mathrm{~min}$ later. The measurement conditions were as follows: power: $1 \mathrm{~mW}$, modulation frequency: $5 \times 100 \mathrm{kHz}$, modulation width: $0.8 \mathrm{mT}$, sweep width: $10 \mathrm{mT}$, sweep time: $30 \mathrm{sec}$, temperature: $298 \mathrm{~K}$.

\section{Hydroxyl radical scavenging assay}

Hydroxyl radicals were generated via the Fenton reaction, 
and reacted rapidly with nitrone spin trap DMPO; the resultant DMPO-OH adducts was detectable with an ESR spectrometer (Rosen \& Rauckman, 1984). The reaction mixtures containing $0.02 \mathrm{~mL}$ of $0.3 \mathrm{M}$ DMPO, $0.02 \mathrm{~mL}$ of $10 \mathrm{mM} \mathrm{FeSO}_{4}$ and $0.02 \mathrm{~mL}$ of $10 \mathrm{mM} \mathrm{H}_{2} \mathrm{O}_{2}$ were mixed with the tested sample $(0.02 \mathrm{~mL})$. The solution was then transferred into a $100 \mu \mathrm{L}$ teflon capillary tube and the spin adduct was measured on a JES-FA ESR spectrometer (JOEL, Tokyo, Japan) exactly 2.5 min later. The measurement conditions were as follows: power: $1 \mathrm{~mW}$, modulation frequency: $1 \times 100 \mathrm{kHz}$, modulation width: $0.2 \mathrm{mT}$, sweep width: $10 \mathrm{mT}$, sweep time: $30 \mathrm{sec}$, temperature: $298 \mathrm{~K}$.

\section{Alkyl radical scavenging assay}

Alkyl radicals were generated via AAPH. The reaction mixtures containing $0.02 \mathrm{~mL}$ of deionized $\mathrm{H}_{2} \mathrm{O}, 0.02 \mathrm{~mL}$ of $40 \mathrm{mM}$ AAPH and $0.02 \mathrm{~mL}$ of $40 \mathrm{mM}$ POBN were mixed with the tested samples $(0.02 \mathrm{~mL})$. The solution was then incubated for $30 \mathrm{~min}$ at $37^{\circ} \mathrm{C}$ in a water bath (Hiramoto et al., 1993) and transferred into a $100 \mu \mathrm{L}$ teflon capillary tube. The spin adduct was recorded on JES-FA ESR spectrometer (JOEL, Tokyo, Japan). The measurement conditions were as follows: power: $7 \sim 8 \mathrm{~mW}$, modulation frequency: $5 \times 100 \mathrm{kHz}$, modulation width: $0.2 \mathrm{mT}$, sweep width: $10 \mathrm{mT}$, sweep time: $30 \mathrm{sec}$, temperature: $298 \mathrm{~K}$.

\section{Cell culture}

Vero cells (monkey kidney cell line) were grown in DMEM supplemented with $10 \%$ heat-inactivated fetal bovine serum, streptomycin $\left(100 \mathrm{mg} \mathrm{mL}^{-1}\right)$ and penicillin $\left(100 \mathrm{U} \mathrm{mL}^{-1}\right)$. The cultures were maintained at $37^{\circ} \mathrm{C}$ in a $5 \% \mathrm{CO}_{2}$ incubator.

\section{Determination of cell viability (MTT assay)}

Vero cells were seeded in a 96-well plate at a concentration of $1 \times 10^{5}$ cells $\mathrm{mL}^{-1}$. Sixteen hrs after seeding, the cells were treated with ethyl acetate (T-EA) and aqueous (T-WE) extracts of various concentrations $(2.5,5.0$ and $\left.10.0 \mu \mathrm{g} \mathrm{mL}^{-1}\right)$. The cells were then incubated for an additional $24 \mathrm{~h}$ at $37^{\circ} \mathrm{C}$. MTT stock solution $(50 \mu \mathrm{L}$; $2 \mathrm{mg} \mathrm{mL} \mathrm{mL}^{-1}$ in PBS) was then added to each well to a total reaction volume of $250 \mu \mathrm{L}$. After $3 \mathrm{~h}$ of incubation, the plates were centrifuged $(800 \mathrm{~g}, 5 \mathrm{~min})$ and the supernatants were aspirated. The formazan crystals in each well were dissolved in $150 \mu \mathrm{L}$ of dimethylsulfoxide (DMSO) and the absorbance was measured at $540 \mathrm{~nm}$ using ELISA plate reader.

\section{Statistical analysis}

All the data were expressed as mean \pm standard deviation of three determinations. Statistical comparison was

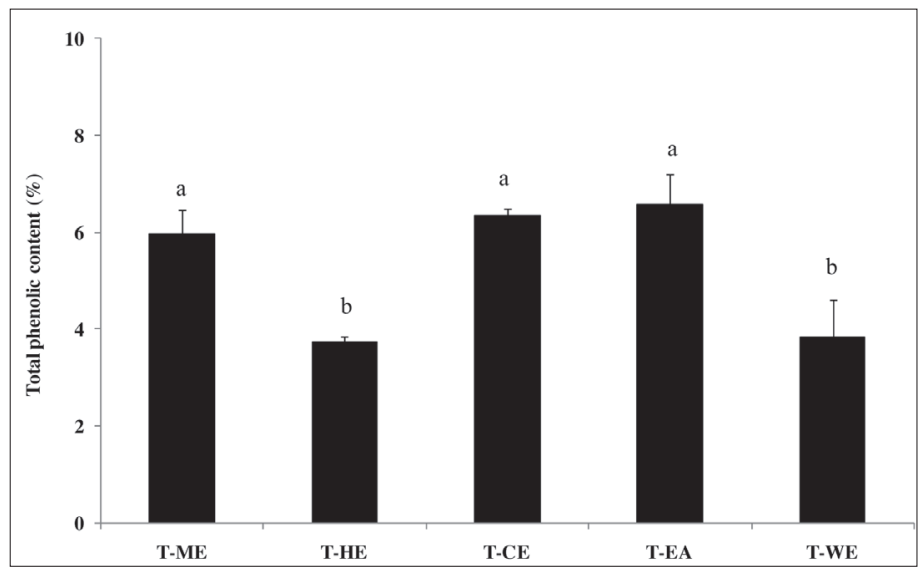

Figure 1: Total phenolic content (TPC \%) in different solvent extracts from thebu plant leaves

Methanol extract (T-ME); n-hexane extract (T-HE); chloroform extract (T-CE); ethyl acetate extract (T-EA); aqueous extract (T-WE)

Values are mean $\pm \mathrm{SD}$ of three determinations.

Values with different letters are significantly different at $\mathrm{p}<0.05$ as analysed by DMRT. 
performed using one-way analysis of variance followed by Duncan's multiple range test (DMRT). Probability values of less than $0.05(\mathrm{p}<0.05)$ were considered as significant.

\section{RESULTS}

\section{Total phenolic content (TPC)}

The highest TPC (\%) was reported as 6.57 (\%) from the TEA extract. T-CE and T-ME extracts also showed a similar TPC (\%) of 6.35 and $5.96(\%)$, respectively and did not significantly differ from the T-EA extract. However, the T-HE and T-WE extracts reported significantly lower TPC values of 3.72 and $3.83(\%)$, respectively (Figure 1).

\section{DPPH radical scavenging activity}

DPPH chemicals generate stable free radicals and are widely used to test the antioxidant activity of compounds or extracts of food materials, as free radical scavenging properties or hydrogen donor capacity. The antioxidant activity of different organic solvent extracts of thebu plant leaves were determined using DPPH radicals by the ESR method (Figure 2). Among the thebu extracts, T-ME, T-HE, T-EA and T-WE fractions showed around $80 \%$ DPPH scavenging activity at $2.0 \mathrm{mg} \mathrm{mL}^{-1}$ concentration, whereas T-CE showed around $74 \%$ of DPPH scavenging activity at the same concentration. In particular, T-WE fraction indicated a remarkable dose dependant increase of DPPH scavenging activity with increasing

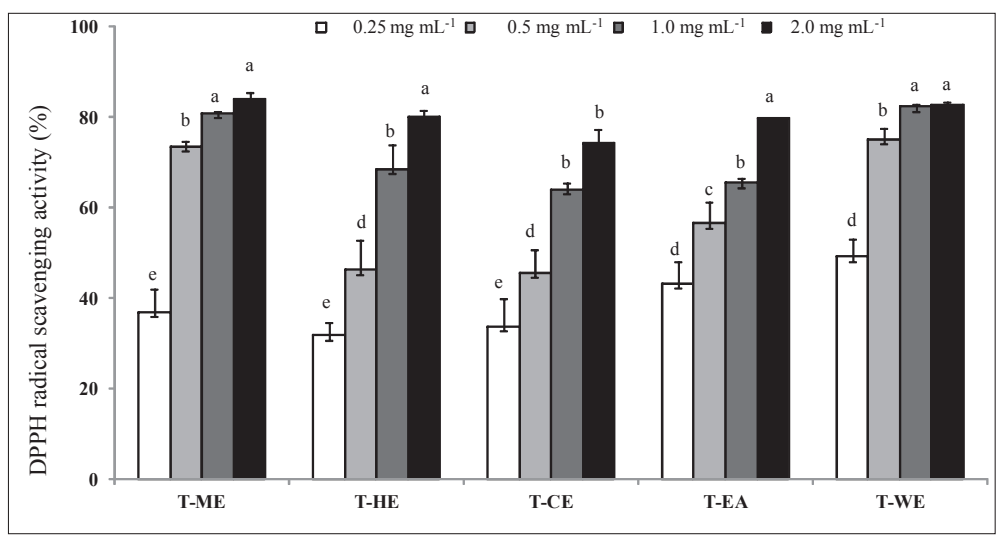

Figure 2: DPPH radical scavenging activity of different solvent extracts from thebu plant leaves viz; methanol extract (T-ME); n-hexane extract (T-HE); chloroform extract (T-CE); ethyl acetate extract (T-EA) and aqueous extract (T-WE). Different colour bars show the different concentrations treated from extracts. Values are mean $\pm \mathrm{SD}$ of three determinations.

Values with different letters are significantly different at $\mathrm{p}<0.05$ as analysed by DMRT.

Table 1: Radical scavenging activities of different solvent extractions from thebu (Costus speciosus) plant leaves a

\begin{tabular}{lcccccc}
\hline Samples & T-ME & T-HE & T-CE & T-EA & T-WE & AA \\
\hline IC $_{50}$ values $\left(\mathrm{mg} \mathrm{mL}^{-1}\right)^{\mathrm{b}}$ & & & & & & \\
DPPH & $0.320 \pm 0.01$ & $0.607 \pm 0.02$ & $0.639 \pm 0.05$ & $0.403 \pm 0.02$ & $0.110 \pm 0.01$ & $0.0035 \pm 0.003$ \\
Hydroxyl & $0.258 \pm 0.02$ & $0.273 \pm 0.01$ & $0.138 \pm 0.03$ & $0.046 \pm 0.002$ & $0.986 \pm 0.04$ & $0.0033 \pm 0.005$ \\
Alkyl & $0.141 \pm 0.01$ & $0.082 \pm 0.001$ & $0.134 \pm 0.03$ & $0.055 \pm 0.004$ & $0.203 \pm 0.04$ & $0.0123 \pm 0.006$ \\
\hline
\end{tabular}

${ }^{\text {a }}$ The values of $\mathrm{IC}_{50}$ were determined by triplicate individual experiments. Values are mean $\pm \mathrm{SD}$ of three determinations

${ }^{\mathrm{b}}$ The concentration of sample required to scavenge $50 \%$ of the radical scavenging activity.

Methanol extract (T-ME); n-hexane extract (T-HE); chloroform extract (T-CE); ethyl acetate extract (T-EA); aqueous extract (T-WE) and ascorbic acid (AA) 


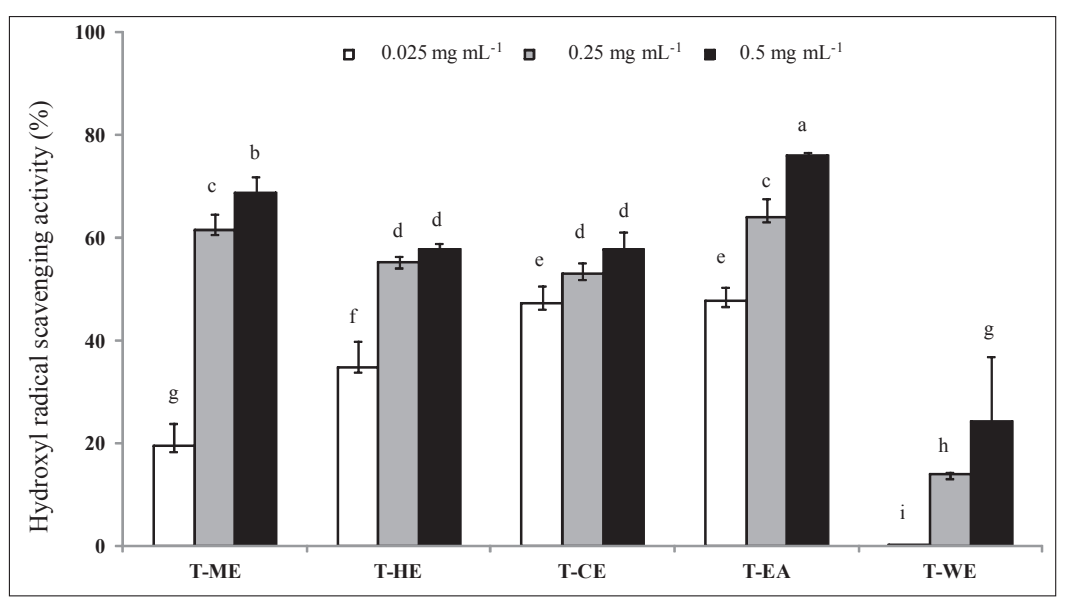

Figure 3: Hydroxyl radical scavenging activity of different solvent extracts from thebu plant leaves viz; Methanol extract (T-ME); n-hexane extract (T-HE); chloroform extract (T-CE); ethyl acetate extract (T-EA) and aqueous extract (T-WE).

Different colour bars show the different concentrations treated from extracts.

Values are mean $\pm \mathrm{SD}$ of three determinations. Values with different letters are significantly different at $\mathrm{p}<0.05$ as analysed by DMRT.

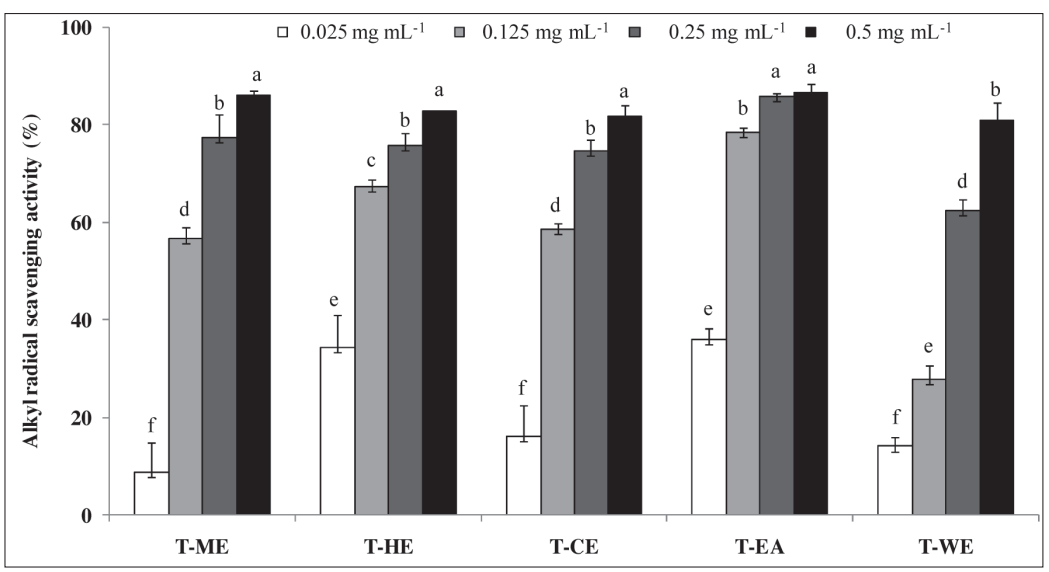

Figure 4: Alkyl radical scavenging activity of different solvent extracts from thebu plant leaves viz; Methanol extract (T-ME); n-hexane extract (T-HE); chloroform extract (T-CE); ethyl acetate extract (T-EA) and aqueous extract (T-WE)

Different colour bars show the different concentrations treated from extracts.

Values are mean $\pm \mathrm{SD}$ of three determinations. Values with different letters are significantly different at $\mathrm{p}<0.05$ as analysed by DMRT.

concentration from 0.25 to $2.0 \mathrm{mg} \mathrm{mL}$. It was noted that both T-ME and T-WE fractions exhibited a similar pattern of DPPH scavenging activity, although the $\mathrm{IC}_{50}$ value was the lowest in the T-WE fraction $(0.110 \pm$ $0.01 \mathrm{mg} \mathrm{mL}^{-1}$ ) and therefore considered the highest active fraction compared to the other thebu extracts. However, ascorbic acid, which was used as a commercial antioxidant in this study reported an $\mathrm{IC}_{50}$ value of 0.0035 $\pm 0.003 \mathrm{mg} \mathrm{mL}^{-1}$ (Table 1).

\section{Hydroxyl radical scavenging activity}

Hydroxyl radicals are highly reactive oxygen species, which are capable of causing damages to DNA and other biological tissues. Moreover, they can initiate the lipid peroxidation process by abstracting hydrogen atoms from unsaturated fatty acids. Therefore in this study, thebu plant extracts were assessed to determine the potentiality of hydroxyl scavenging activity by ESR method (Figure 3). 


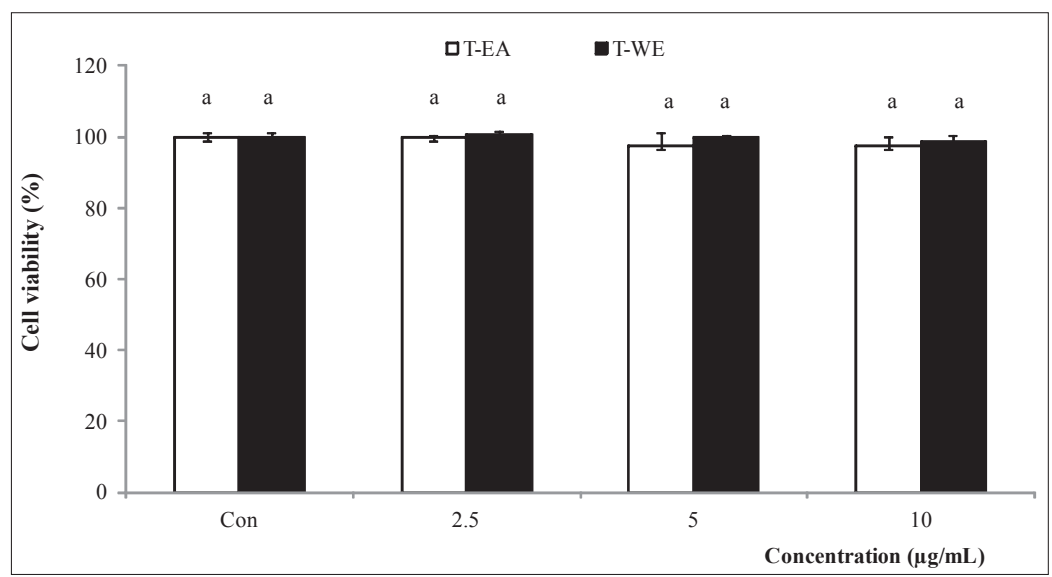

Figure 5: The cytotoxic effect of the ethyl acetate (T-EA) and aqueous (T-WE) extracts on the viability on vero cells.

Values are expressed as means $\pm \mathrm{SD}$ in triplicate experiments. Values with different letters are significantly different at $\mathrm{p}<0.05$ as analysed by DMRT.

According to the results (Table 1), the T-EA fraction indicated significantly higher hydroxyl scavenging properties $\left(\mathrm{IC}_{50}\right.$ value $\left.0.046 \pm 0.002 \mathrm{mg} \mathrm{mL}^{-1}\right)$ compared to the other fractions. It showed about $75 \%$ of hydroxyl scavenging activity at $0.5 \mathrm{mg} \mathrm{mL}$ - concentration. All the other fractions showed a significant hydroxyl radical scavenging activity dose-dependently. The determined $\mathrm{IC}_{50}$ values are given in Table 1. However, the commercial antioxidant (ascorbic acid) showed the strongest scavenging activity on hydroxyl radicals $\left(\mathrm{IC}_{50}\right.$ value $0.0033 \pm 0.005 \mathrm{mg} \mathrm{mL}^{-1}$ ).

\section{Alkyl radical scavenging activity}

The treatment of AAPH with POBN at $37^{\circ} \mathrm{C}$ for $30 \mathrm{~min}$ results in the generation of alkyl radicals. The alkyl radical scavenging properties of the thebu extracts derived by different solvents were determined in this study. The T-EA fraction had the highest alkyl radical scavenging activity ( $86 \%$ at $0.5 \mathrm{mg} \mathrm{mL}^{-1}$ concentration), but did not show a significant difference at $0.25 \mathrm{mg} \mathrm{mL}^{-1}$ concentration (Figure 4). However, all the other fractions showed a significant increase in the alkyl radical scavenging activity with increasing concentrations. According to the $\mathrm{IC}_{50}$ values, the strongest activity was shown by the T-EA fraction $\left(\mathrm{IC}_{50}\right.$ value $\left.0.055 \pm 0.004 \mathrm{mg} \mathrm{mL}^{-1}\right)$, which was higher than the ascorbic acid $\mathrm{IC}_{50}$ value $(0.0123 \pm 0.006$ $\mathrm{mg} \mathrm{mL} \mathrm{m}^{-1}$ ) (Table 1).

\section{Effect of T-EA and T-WE fractions on cell viability in normal cells}

Vero cells were treated with different concentrations of T-EA and T-WE fractions to determine the effect of cytotoxicity for further experiments. In this in vitro assay, both fractions resulted in over $98 \%$ cell survivability at all the concentrations $\left(2.5,5.0\right.$ and $\left.10.0 \mu \mathrm{g} \mathrm{mL}^{-1}\right)$ tested (Figure 5). Therefore, T-EA and T-WE fractions do not exhibit cytotoxic effects at the treated concentrations against normal cells and can be used for further in vitro experiments.

\section{DISCUSSION}

Reactive oxygen species (ROS) are the major causative agents for oxidative stress due to imbalances between the natural antioxidant enzymes and ROS activities in the human body. Therefore, antioxidant compounds from food sources play an important role by eliminating these reactive molecules and reducing the risk of cancers, heart disease and diabetes mellitus (Kang et al., 2012). The antioxidant value of many medicinal plants has been widely characterized and commercially exploited (Li et al., 2008; Lin et al., 2009; Kesarwani \& Gupta, 2013).

Vijayalakshmi and Sarada (2008) have reported that the methanolic extracts of the peel of the stem and root of thebu plant (C. specious) showed a higher hydroxyl radical scavenging activity compared to the commercial antioxidants. In another study, different solvent extracts of the thebu rhizomes have been evaluated for in vitro antioxidant activity and the results have indicated that the benzene extracts contain the highest total phenolic content and the respective antioxidant activity (Nehete et al., 2010). However, the medicinal value of the C. specious 
leaf extracts has not been documented. Therefore in this study, the most sensitive, direct and accurate method to detect the free radical scavenging activity, the electron spin resonance (ESR) technique based spectroscopy, was used to monitor the reactive species, including DPPH, hydroxyl and alkyl radicals scavenging activity compared to the commercial antioxidant ascorbic acid at room temperature (Guo et al., 1999; Sharma \& Bhat, 2009).

Based on the identified radical scavenging properties, the strongest scavenging activity was reported in the ethyl acetate fraction (T-EA) among the thebu extracts, and the determined $\mathrm{IC}_{50}$ values were $0.046 \pm 0.002$ and 0.055 $\pm 0.004 \mathrm{mg} \mathrm{mL}^{-1}$ against hydroxyl and alkyl radicals, respectively. T-WE fraction indicated the highest DPPH radical scavenging activity with an $\mathrm{IC}_{50}$ value of $0.110 \pm$ $0.01 \mathrm{mg} \mathrm{mL}^{-1}$. In addition, the T-HE fraction also reported the highest alkyl radical scavenging activity with $\mathrm{IC}_{50}$ value $0.082 \pm 0.001 \mathrm{mg} \mathrm{mL}^{-1}$. However, the commercial antioxidant used in this study indicated the strongest antioxidant activity tested against DPPH and hydroxyl compared to the thebu leaf extracts.

Most of the previous studies have supported that the attributed antioxidant activity is based on the total polyphenol contents of the respective sample. Chen et al. (2008) have shown that the methanolic extracts of the thebu plant rhizomes indicated profound DPPH radical scavenging and antimicrobial activity compared to the other Zingiberaceae plants tested. In fact, these bioactivities were attributed to the total phenolic contents, which were determined in the extracts. The antioxidant capacities of 45 medicinal plants were correlated with the total phenolic contents and indicated as the major contributor for the antioxidant activity of the plants $(\mathrm{Li}$ et al., 2008). In this study, the observed total phenolic contents of the thebu extracts were evidenced for the assessed antioxidant activity. Among the T-EA, T-CE and T-ME fractions, the determined TPC values were not significantly different. However, T-WE and T-HE fractions were significantly lower than the TPC values of the other fractions. The radical scavenging activities were higher in T-WE and T-HE fractions compared to the other extracts. Therefore, the identified antioxidant capacity of the thebu extracts can be associated with the phenolic compounds as well as other secondary metabolites.

Quantification studies of the C. speciosus rhizome ethanolic extracts using HPTLC method has reported the presence of phenolic compounds, steroids, saponin glycosides and sugars (Verma \& Khosa, 2012). In particular, the identified phytochemicals in C. specious and $C$. igneus also indicated positive evidence for flavonoids, alkaloids, terpenoids, steroids, saponins and phenolic compounds (Devi \& Urooj, 2009). Zingiberaceae plants contain many compounds such as terpens, steroids, flavonoids, carotenoids and phytoestrogens (Chen et al., 2008) and these secondary metabolites are furnished with biological activities including antifungal, antiinflammatory, antioxidant and insecticidal activity (Sirat et al., 1996). Bavarva and Narasimhacharya (2008) have reported that $C$. specious rhizome ethanolic extracts have the potency for antihyperglycaemic, antihyerlipidimic and antioxidant activities. The methanolic extract of C. afer. Ker leaf was investigated for pharmacological activities in vitro and in vivo, and has reported anesthetic, antihyperglycaemic and blood glucose lowering activity (Anaga et al., 2004).

Different organic solvent soluble extracts of the Sri Lankan thebu plant leaf showed the potentiality of free radical scavenging activities in ESR method for the first time. Furthermore, the determined total phenolic content of the thebu leaf extracts indicated some correlation with the respective antioxidant activity. The MTT assay confirmed that both T-WE and T-EA fractions can be used for in vitro experiments without cytotoxic effects. In conclusion, the Sri Lankan thebu plant leaf extracts can be employed as a good candidate for future therapeutic uses.

\section{REFERENCES}

1. Anaga A.O., Njoku C.J., Ekejiuba E.S., Esiaka M.N. \& Asuzu I.U. (2004). Investigation of the methanolic leaf extract of Costus afer. Ker for pharmacological activities in vitro and in vivo. Phytomedicine 11: $242-248$.

DOI: http://dx.doi.org/10.1078/0944-7113-00349

2. Banadara B.M.R., Feranando I.H.S., Hewage C.M. \& Karunaratne V. (1989). Antifungal activity of some medicinal plants of Sri Lanka. Journal of the National Science Council of Sri Lanka 17: 1 - 13.

3. Bavarva J.H. \& Narasimhacharya A.V.R.L. (2008). Antihyperglycemic and hypolipidimic effects of Costus speciosus in Alloxan induced diabetic rats. Phytotherapy Research 22: $620-626$.

DOI: http://dx.doi.org/10.1002/ptr.2302

4. Chandler S.F. \& Dodds J.H. (1983). The effect of phosphate, nitrogen, and sucrose on the production of phenolics and solasidine in callus cultures of Solanum laciniatum. Plant Cell Reports 2: $105-110$.

DOI: http://dx.doi.org/10.1007/BF00270105

5. Chen I.N., Chang C.C., Ng C.C., Wang C.Y., Shyu Y.T. \& Chang T.L. (2008). Antioxidant and antimicrobial activity of Zingiberaceae plants in Taiwan. Plant Foods for Human Nutrition 63: $15-20$.

DOI: http://dx.doi.org/10.1007/s11130-007-0063-7 
6. Devi V.D. \& Urooj A. (2009). Nutrient profile and antioxidant components of Costus speciosus Sm. and Costus igneus Nak. Indian Journal of Natural Products and Resources 1: $116-118$.

7. Finkel T. \& Holbrook N.J. (2000). Oxidants, oxidative stress and the biology of ageing. Nature 408: $239-247$. DOI: http://dx.doi.org/10.1038/35041687

8. Gunathilaka A.A.L., Sotheeswaran S. \& Balasubramanium S. (1978). Economically useful plants of Sri Lanka II: commercially important steroidal sapogenins from Sri Lanka plants. Journal of the National Science Council of Sri Lanka 6: 121 - 128.

9. Guo Q., Zhao B., Shen S., Hou J., Hu J. \& Xin W. (1999). ESR study on the structure-antioxidant activity relationship of tea catechins and their epimers. Biochimica et Biophysica Acta 1427: 13 - 23.

10. Heo S.J. \& Jeon Y.J. (2008). Radical scavenging capacity and cytoprotective effect of enzymatic digests of Ishige okamurae. Journal of Applied Phycology 20: 1087 1095.

DOI: http://dx.doi.org/10.1007/s10811-008-9320-x

11. Hiramoto K., Johkoh H., Sako K.I. \& Kikugawa K. (1993). DNA breaking activity of the carbon-centered radical generated from 2,2'-azobis(2-amidinopropane) hydrochloride (AAPH). Free Radical Research Communications 19: 323 - 332.

DOI: http://dx.doi.org/10.3109/10715769309056521

12. Inayatullah S., Prenzler P.D., Obied H.K., Rehman A.U. \& Mirza B. (2012). Bioprospecting traditional Pakistani medicinal plants for potent antioxidants. Food Chemistry 132: $222-229$.

DOI: http://dx.doi.org/10.1016/j.foodchem.2011.10.060

13. Kang M.C., Kim E.A., Kang S.M., Wijesinghe W.A.J.P., Yang X., Kang N. \& Jeon Y.J. (2012). Thermostability of marine polyphenolic antioxidant dieckol, derived from the brown seaweed Ecklonia cava. Algae 27: 205 - 213. DOI: http://dx.doi.org/10.4490/algae.2012.27.3.205

14. Kesarwani K. \& Gupta R. (2013). Bioactivity enhancers of herbal origin: an overview. Asian Pacific Journal of Tropical Biomedicine 3: $253-266$.

15. Kim S.Y., Je J.Y. \& Kim S.K. (2007). Purification and characterization of antioxidant peptide from hoki (Johnius belengerii) frame protein gastrointestinal digestion. The Journal of Nutritional Biochemistry 18: 31 - 38. DOI: http://dx.doi.org/10.1016/j.jnutbio.2006.02.006

16. Li H.B., Wong C.C., Cheng K.W. \& Chen F. (2008). Antioxidant properties in vitro and total phenolic contents in methanol extracts from medicinal plants. LWT-Food
Science and Technology 41: 385 - 390.

DOI: http://dx.doi.org/10.1016/j.lwt.2007.03.011

17. Lin K.W., Liu C.H., Tu H.Y., Ko H.H. \& Wei B.L. (2009). Antioxidant prenylflavonoids from Artocarpus communis and Artocarous elasticus. Food Chemistry 115: 558 562.

DOI: http://dx.doi.org/10.1016/j.foodchem.2008.12.059

18. Nanjo F., Goto K., Seto R., Suzuki M., Sakai M. \& Hara Y. (1996). Scavenging effects of tea catechins and their derivatives on 1,1-diphenyl-2-picrylydrazyl radical. Free Radical Biology and Medicine 21: 895 - 902.

19. Nehete J., Bhatia M. \& Narkhede M. (2010). In vitro evaluation of antioxidant activity and phenolic contents of Costus speciosus (Koen) J.E.Sm. Iranian Journal of Pharmacological Research 9: $271-277$.

20. Qian Z.J., Jung W.K. \& Kim S.K. (2008). Free radical scavenging activity of a novel antioxidative peptide purified from hydrolysate of bullfrog skin, Rana catesbeiana Shaw. Bioresources Technology 99: 1690 - 1698.

DOI: http://dx.doi.org/10.1016/j.biortech.2007.04.005

21. Rosen G.M. \& Rauckman E.J. (1984). Spin trapping of superoxide and hydroxyl radicals. Methods in Enzymology (ed. L. Packer), pp. 198 - 209. Academic Press, Orlando, USA.

22. Sharma O.P. \& Bhat T.K. (2009). DPPH antioxidant assay revisited. Food Chemistry 113: $1202-1205$. DOI: http://dx.doi.org/10.1016/j.foodchem.2008.08.008

23. Sirat H.M., Rahman A.A., Itokawa H. \& Morita H. (1996). Constituents of the rhizomes of two Alpinia species of Malaysia. Planta Medica 62:188 - 189. DOI: http://dx.doi.org/10.1055/s-2006-957857

24. Srivastava S., Singh P., Mishra G., Jha K.K. \& Khosa R.L. (2011). Costus speciosus (Keukand): a review. Der Pharmacia Sinica 2: 118 - 128.

25. Subasinghe H.W.A.S., Hettihewa L.M. \& Gunawardena S. (2012). Rapid onset action of Costus speciosus leaf extracts on insulin resistance in experimental wistar rats. Proceedings of the Annual Scientific Sessions of Faculty of Medical Sciences, University of Sri Jayewardenepura.

26. Verma N. \& Khosa R.L. (2012). Development of standerization paramaeters of Costus speciosus rhizomes with special references to its pharmacological and HPTLC studies. Asian Pacific Journal of Tropical Biomedicine: s276 - s283.

27. Vijayalakshmi M.A. \& Sarada N.C. (2008). Screening of Costus speciosus extracts for antioxidant activity. Fitoterapia 79: 197 - 198.

DOI: http://dx.doi.org/10.1016/j.fitote.2007.11.014 